\title{
Trauma Surgery \& Acute Care Open \\ Cardiac air emboli secondary to traumatic skull fractures: a rare, successful aspiration in the trauma bay
}

\author{
Abin Sajan, Hazim Hakmi, Adam Goldstein, Yesha Maniar, Amir H Sohail, \\ D’Andrea Joseph, Patrizio Petrone, Ricardo Jacquez
}

Department of General Surgery, NYU Langone Hospital - Long Island, Mineola, New York, USA

Correspondence to Dr Abin Sajan; abin.sajan01@ gmail.com (c) Author(s) (or their employer(s)) 2021. Re-use permitted under CC BY-NC. No commercial re-use. See rights and permissions. Published by BMJ.

To cite: Sajan A, Hakmi H, Goldstein A, et al. Trauma Surg Acute Care Open 2021:6:e000787.

\section{CASE SUMMARY}

An elderly patient aged 70 presented with a level I trauma after being struck by a motor vehicle traveling at unknown speed. The patient was found down and unresponsive by emergency medical services (EMS) with a Glasgow Coma Scale (GCS) score of 3 and was subsequently intubated. An intraosseous (IO) catheter was placed by EMS in the left proximal tibia and fluid resuscitation was started en route.

On primary survey, the airway was secured with orotracheal intubation; bilateral breath sounds were auscultated; and correct placement was confirmed with end tidal $\mathrm{CO}_{2}$. Distal pulses were noted with a blood pressure of $135 / 70 \mathrm{~mm} \mathrm{Hg}$ and a heart rate of 94 beats/min. The patient's GCS score improved to 7T (E1V1TM5) in the trauma bay with localization to pain of the bilateral upper extremities. Pupils were $3 \mathrm{~mm}$ symmetric and reactive. Secondary survey was significant for bilateral periorbital hematomas and epistaxis, distended abdomen without signs of external trauma, and bilateral knee abrasions. Chest and pelvic $\mathrm{X}$-rays failed to show displaced fractures. The patient was subsequently taken for complete body CT scan. A finding of moderate volume of air in the right ventricle $(6 \mathrm{~cm}$ widest and $0.8 \mathrm{~cm}$ deepest) and main pulmonary artery (figure 1 ) was immediately noted. This finding was coincident with the onset of hypotension and worsening oxygenation. Other notable injuries included a left subdural hematoma with mild subfalcine herniation, bilateral subarachnoid hemorrhages, bifrontal cerebral contusions, and a left frontal displaced skull fracture with significant pneumocephalus. A summary of all injuries is listed in table 1 .

\section{WHAT WOULD YOU DO?}

A. Resuscitate further, Trendelenburg positioning, and watchful waiting.

B. Place patient in Trendelenburg position and aspirate the air embolus.
C. Go to the operating room for cranial decompression.

D. Consider emergent hyperbaric oxygen therapy.

\section{WHAT WE DID AND WHY}

The patient was immediately positioned in Trendelenburg position, and a right internal jugular vein triple lumen central venous catheter was emergently placed and advanced to a depth sufficient to reside within the right heart (around $16 \mathrm{~cm}$ ). Immediately $60 \mathrm{cc}$ of blood mixed with air was aspirated and autotransfused back to the patient through a peripheral intravenous (PIV) site. Care was taken to ensure the autotransfusion contained no air. Before transferring the patient to the surgical intensive care unit (SICU), an intracranial pressure monitor was placed. En route to SICU, a repeat CT of the chest was performed, which demonstrated resolution of the previously noted intracardiac air. The patient was adequately resuscitated during this time to expand the central venous pressure and to reduce the pressure gradient at the fracture site to prevent further air embolism.

Air embolism can cause severe end organ damage in the absence of collateral supply. Venous air emboli can directly migrate to pulmonary circulation or indirectly reach the arterial system via a right to left cardiac shunt, capillary reabsorption, etc. The symptoms of venous air emboli rely on the amount of air entry as minor cases often resolve spontaneously, while severe cases can result in cardiopulmonary compromise.

In the setting of venous air emboli from skull fractures, two mechanisms have been proposed to describe air absorption. The first involves direct vessel injury resulting in the absorption of air through the endothelium. The second mechanism involves the absorption of air through the arachnoid villi tubules. The arachnoid tubules generally

\begin{tabular}{ll}
\hline Table 1 & Summary of all reported injuries \\
\hline Modality & Injury \\
\hline CXR & $\begin{array}{l}\text { Elevated appearance of the aortic knob likely reflecting tortuosity as the margins appear well defined; lungs and pleural spaces are grossly clear; no } \\
\text { displaced fractures; no subcutaneous gas or radiopaque foreign body. }\end{array}$ \\
CT of the head & $\begin{array}{l}\text { 1. } \\
\text { Left subdural hematoma causing mild subfalcine herniation toward the right bilateral subarachnoid hemorrhage and bifrontal cerebral contusions, } \\
\text { extensive pneumocephalus. }\end{array}$ \\
& 2. $\begin{array}{l}\text { Multiple mid-face fractures including left zygomaticomaxillary complex, bilateral frontal bone fractures involving anterior and posterior tables, } \\
\text { bilateral anterior nasal spines, and bilateral anterior and lateral maxillary wall fractures; no ocular injury. }\end{array}$ \\
CT of the chest & 1. $\begin{array}{l}\text { Air is present in the right ventricle and within the main pulmonary artery, a risk for air embolism. } \\
\text { Non-displaced left anterior fourth and seventh rib fractures, minimally displaced left anterolateral fifth and sixth rib fractures, no right-sided rib } \\
\text { fractures. }\end{array}$
\end{tabular}

CXR, chest $X$-ray. 


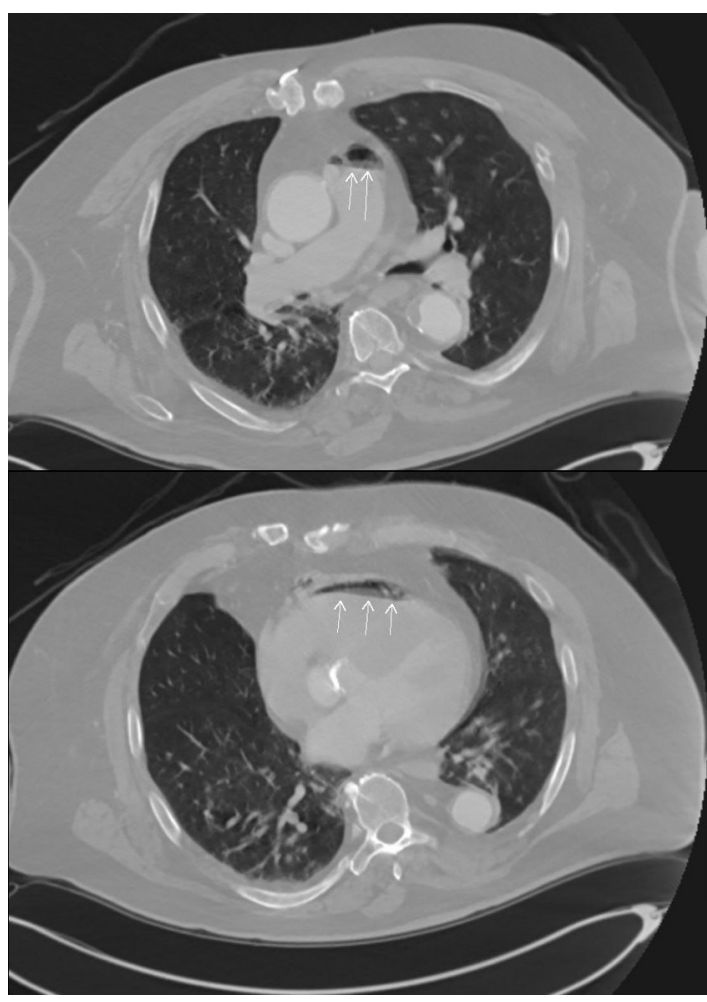

Figure 1 Initial CT demonstrating air in the right pulmonary artery (top, arrows) and right ventricle (bottom, arrows).

function as valves to prevent reflux of cerebrospinal fluid into the meningeal system but can be overwhelmed in the setting of trauma leading to air absorption.

It is important to note that air can be introduced into the venous system from external sources such as PIV lines, catheters, and other sources, including the level I rapid infuser. In the current case, the patient presented with bilateral 18 G PIVs and an IO catheter in the left proximal tibia. An intravenous source is unlikely as there was no evidence of peripheral air embolism, crepitus, nor ischemia due to air entrapment. An IO source of air is also unlikely with only two previously reported cases in the pediatric literature and no evidence of peripheral air embolism on exam as demonstrated in those cases. Although additional arterial and central lines were placed on the patient, these were placed after the initial CT had identified the intracardiac air emboli.

Given that patients with intracardiac air embolism are often diagnosed after air has already reached target circulation, for example, pulmonary or cerebral circulation, treatment options are limited and include close hemodynamic monitoring, patient positioning, air evacuation, and hyperbaric oxygen therapy. Although hyperbaric oxygen therapy is commonly used in the arterial system, it has limited use in the venous system. The current case describes a unique opportunity to visualize air before it obstructed end organ circulation, as the initial CT demonstrated isolated air in the right heart without significant pulmonary emboli nor cardiac ischemia. Given the urgent and unique nature of the case with the ability to visualize air before cardiopulmonary collapse, we emergently placed an intracardiac catheter to potentially aspirate the air. Although the technique has been previously reported in atraumatic patients, catheter aspiration in the trauma setting has not been well studied.

Contributors $A S, H H$, and $A G$ wrote the manuscript with support from $Y M$ and AHS. DAJ helped supervise the project. PP was in charge of editing. RJ supervised the whole project.

Funding The authors have not declared a specific grant for this research from any funding agency in the public, commercial or not-for-profit sectors.

Competing interests None declared.

Patient consent for publication Not required.

Provenance and peer review Not commissioned; externally peer reviewed.

Open access This is an open access article distributed in accordance with the Creative Commons Attribution Non Commercial (CC BY-NC 4.0) license, which permits others to distribute, remix, adapt, build upon this work non-commercially, and license their derivative works on different terms, provided the original work is properly cited, appropriate credit is given, any changes made indicated, and the use is non-commercial. See: http://creativecommons.org/licenses/by-nc/4.0/. 